\title{
PROGRAM PENGEMBANGAN KEWIRAUSAHAAN DI FAKULTAS BIOINDUSTRI, UNIVERSITAS TRILOGI 2019 - 2021
}

\author{
Maulidian $^{1}$, Inanpi Hidayati Sumiasih ${ }^{2}$, Mutiara Dewi Puspitawati ${ }^{2}$, Hermawan Seftiono ${ }^{3}$ \\ ${ }^{1}$ Program Studi Agribisnis Universitas Trilogi \\ ${ }^{2}$ Program Studi Agroekoteknologi Universitas Trilogi \\ ${ }^{3}$ Program Studi Ilmu dan Teknologi Pangan Universitas Trilogi
}

maulidian@trilogi.ac.id, inanpihs@trilogi.ac.id,mutiara.dewi@trilogi.ac.id, hermawan_seftiono@trilogi.ac.id

\begin{abstract}
Abstrak
Universitas Trilogi memiliki visi untuk mencetak generasi teknososiopreneur yang unggul. Visi ini dicapai melalui program tri darma perguruan tinggi. Salah satu wujud untuk mengimplementasikan visi ini, Fakultas Bioindustri Unviersitas Trilogi di bawah Pusat Pengembangan Kapasitas Wirausaha Bioindustri membuat program pengembangan kewirausahaan untuk para mahasiswa dan alumni. Tujuan dari kegiatan ini yaitu untuk mempersiapkan para mahasiswa dan alumni fakultas bioindustri agar dapat menyelesaikan permasalahan bangsa melalui inovasi dan kewirausahaan. Metode yang digunakan dalam program ini yaitu penseleksian, pendampingan, pendanaan, pelatihan dan kunjungan perusahaan. Program di danai oleh Kementerian Pendidikan, Kebudayaan, Riset, dan Teknologi Republik Indonesia. Hasil dan dicapai dalam program ini wirausaha-wirausaha yang inovatif dan menyelesaikan permasalahan yang ada. Pada tahun 2019, terdapat 12 usaha yang inovatif yaitu Biocraft, Moodup, Kinuque, Sooci, Mopizza, Isogen, Otel, Mapaya, Bunatea, Muma, Yoshee, dan Nature-B. Tahun 2020 terdapat 12 usaha yang inovatif yaitu Roti Karkus, Burgernesia, Pyong Ktichen, Bubbly Bob's, Fancis Jam, Dalcomy, Vegefish, Albedo Candy, Yubbi Nugget, Indorice, Rainbowlu, dan Saritem. Tahun 2021, terdapat 8 usaha yang inovatif yaitu Roti Mila, Shicimol, Pudding Custom, Ngenyangin, Bakso Frozen Prebiotik, S-Hat, Dapur Kakak Gembira, dan Otakin aja. Program-program yang diberikan memberikan dampak positif bagi para peserta sehingga usaha yang dijalankan saat ini dapat berkembang dengan baik.
\end{abstract}

Kata Kunci : Bioindustri, Inovasi, Pelatihan, Teknososiopreneur, Wirausaha.

\section{PENDAHULUAN}

Universitas Trilogi merupakan salah satu Universitas di DKI Jakarta yang meiliki visi untuk mengembangakn wirausaha sosial berbasis teknologi. Tiga pilar yang menjadi value yaitu teknososiopreneur, kolaborasi, dan kemandirian. Melalui tiga pilar ini diwujudkan kedalam proses pembelajaran di setiap Fakultas, salah satunya adalah Fakultas Bioindustri.

Fakultas Bioindustri memiliki visi dalam pengembangan keilmuan dalam bidang pangan dan pertanian. Fakultas Bioindustri terdiri dari tiga program studi yaitu Agribisnis, Agroekoteknologi, dan Ilmu dan Teknologi Pangan. Ketiga program studi ini berusaha mewujudkan visi dan misi yang 
diturunkan dari Universitas dan Fakultas melalui kegiatnan Tri Dharma Pendidikan Tinggi. Pendidikan yang menekankan pada aspek pembelajaran berkelompok. Penelitian yang berfokus pada pengembangan sektor pangan dan pertanian. Pengabdian yang menyasar pada masyarakat yang bergerak disektor pertanian dan pangan. Adanya integrasi dari setiap kegiatan Tri Dharma Perguruan Tinggi, membantu dalam proses pembelajaran yang dilakukan oleh mahasiswa, terutama untuk mencetak wirausaha baru. Sehingga, Fakultas Bioindustri khususnya, Universitas Trilogi umumnya, melalui program peningkatan kompetensi sumberdaya manusia dapat mendukung program pemerintah dalam mencetak 5 juta wirausaha baru pada tahun 2025 (Sukirman, 2017).

Salah satu wujud nyata proses pembelajaran dalam meningkatan jumlah wirausaha adalah melalui luaran kegiatan perkuliahan yang menghasilkan produk inovasi pangan dan pertanian yang memberikan solusi bagi masyarakat dan lingkungan. Proses ini merupakan salah satu bentuk dalam meningkatkan kemampuan teknikal apabila mahasiswa ingin menjadi seorang wirausaha. Proses pembelajaran tidak hanya sekedar keahlian wirausaha tetapi juga kemampuan teknis dalam menjalankan usaha. Agar para mahasiswa memiliki jiwa kewirausahaan salah satu cara adalah melalui Pendidikan untuk menanamkan keahlian dan perilaku wirausaha (Budi \& Fensi, 2018).

Mahsiswa yang sudah dibekali pembelajaran wirausaha dan teknikalnya, ternyata belum mampu untuk mewujudkan realisasi atau implementasinya. Akan tetapi, permasalahan ini merupakan permasalahan yang umum terjadi. Berdasarkan hasil pengamatan kami, mahasiswamahasiswa masih bingung bagaimana mengimpelentasikan kelanjutan dari proses pembelajaran di kelas. Padahal, untuk mempercepat pertumbuhan ekonomi, dibutuhkan wirausaha sebagai katalis yang agresif (Athia, Saraswati, \& Normaladewi, 2018). Oleh karena itu, Pusat Pengembangan Kapasitas Wirausaha Bioindustri (PPKWB) melihat potensi tersebut, agar produk inovasi yang dihasilkan siap untuk dikomersilkan dan sumberdaya manusia dapat mengembangkan keberlanjutan usahanya. Untuk menciptakan peluang kerja baru mahasiswa sangat membutuhkan sikap, motivasi dan minat berwirausah, sehingga mereka dapat mendayagunakan peluang yang didapatkan (Rosmiati, Junias, \& Munawar, 2015).

PPKWB merupakan salah satu pusat yang

berada di bawah koordinasi dekan fakultas bioindustri yang bertugas untuk mengembangkan kapasitas wirausaha mahasiswa, dosen, dan alumni Fakultas Biondustri Universitas Trilogi. Tugas pokok dan fungsi dari PPKWB sebagai berikut :

1. Mengembangkan kemampuan berperilaku wirausaha dan kemampuan teknikal bagi mahasiswa, dosen, almuni dan masyarakat di lingkungan Fakultas Bioindustri Universitas Trilogi;

2. Memanfaatkan hasil-hasil riset inovatif bidang Pangan dan Pertanian untuk pengembangan usaha;

3. Membangun jejaring untuk meningkatkan kapasitas wirausaha melalui program pemagangan di perusahaan berbasis pangan dan energi terbarukan;

4. Menyiapkan konsep perusahaan pemula (startup company) bidang pangan dan energi terbarukan untuk mahasiswa dan alumni Fakultas Bioindustri Universitas Trilogi.

Berdasarkan permasalahan-permasalahan di atas, maka solusi yang tepat sasaran sangat diperlukan. Oleh karena itu, PPKWB memformulasikan beberapa solusi sebagai jalan keluar agar visi dan misi Universitas Trilogi sebagai kampus penghasil wirausahawan dapat terwujud. Solusi yang diberikan yaitu berupa program pengembangan kewirausahaan di Fakultas Bioindustri, Universitas Trilogi. Adanya program pengembangan kewirausahaan mahasiswa diharapkan mampu memahami bagaimana menjadi seorang wirausaha. Seseorang yang memilih karir menjadi wirausaha tentu suatu pilihan yang menantang karena akan menghadapi berbagai situasi yang penuh dengan ketidakpastian, kegagalan, rintangan, dan bahkan rasa frustasi (Widayati, et al., 2019). Adanya pengalaman akan membangun karakteristik wirausaha pada mahasiswa. Seseorang yang memiliki karakteristik kewirausahaan berarti memiliki kualitas dan sifat konsisten serta memiliki ciri khas tertentu (Setyawati, Nugraha, \& Ainuddin, 2013). Sehingga, tujuan dari program ini yaitu untuk meningkatkan 
kapasitas wirausaha mahasiswa yang telah memiliki produk-produk inovatif agar dapat kembangkan lebih lanjut.

\section{METODE}

Target peserta yaitu mahasiswa dan alumni Fakultas Bioindustri, Universitas Trilogi. Pelaksanaan kegiatan secara terprogram dari tahun 2109 - 2021. Secara umum metode pelaksanaan terdiri dari 3 tahap yaitu persiapan, pelaksanaan, dan evaluasi. Tahap persiapan untuk merencanakan program-program yang akan diberikan dari tahun 2019 - 2021. Tahap pelaksanaan merupakan realisasi kegiatan yang telah direncanakan yaitu berupa seleksi, program pendanaan, program pendampingan, program pelatihan, dan program kunjungan perusahaan. Tahap evaluasi merupakan tahap kegiatan monitoring dan evaluasi setiap pelaksanaan kegiatan dari tahun 2019- 2021.

\section{HASIL DAN PEMBAHASAN}

\section{Persiapan}

Tahap persiapan dihadiri oleh seluruh tim PPKWB. Tim PPKWB mempersiapkan sosialisasi dan seleksi program, program-program yang dilaksanakan, kebutuhan sarana dan prasarana yang diperlukan, evaluasi tenant, dan luaran-luaran yang akan dicapai. Berdasarkan hasil rapat tim PPKWB tahap sosialisasi dilaksanakan pada bulan Januari hingga Februari, seleksi proposal dan wawancara bulan Maret, serta penandatangan program bulan April. Persiapan program-program kegiatan yaitu pemilihan pendamping tenant, penentuan tema dan narasumber program pelatihan, penentuan tempat kunjungan perusahaan dan kebutuhan sarana prasarana yang dibutuhkan. Persiapan program evaluasi tenant yaitu mempersiapkan penilaian tenant yang layak lulus dengan kategori kesiapan produk inovasi, pemasaran, dan kemajuan usaha. Persiapan pada tahap luaran yaitu mempersiapkan luaran-luaran yang diwajibkan oleh Kemendibudristek dalam pelaksanaan program PPK yaitu produk inovasi, publikasi ilmiah, publikasi popular, serta video program kegiatan.

\section{Pelaksanaan Kegiatan}

a. Program Seleksi

Pada tahun 2019, PPKWB mengadakan program seleksi melalui tiga tahap yaitu seleksi proposal, seleksi wawancara, dan seleksi minat dan bakat. Seleksi proposal dilakukan melalui dua cara yaitu pengumpulan proposal bisnis dalam bentuk power point dan pengumpulan video persentasi perencanaan bisnis. Seleksi wawancara dilakukan dengan metode interview secara tatap muka yang dilakukan oleh 4 orang tim PPKWB. Seleksi wawancara untuk menilai kesiapan dan kesungguhan peserta untuk mengikuti program PPKWB 2019. Poin penilaian seleksi wawancara terdiri kemampuan menjelaskan inovasi produk, kemampuan menjelaskan masalah yang ingin diselesaikan dari usaha yang dijalankan, kemampuan menjelaskan bagaimana rencana pemasaran, serta kemampuan menjelaskan peran anggota tim dalam usaha. Seleksi minat dan bakat dilakukan menggunakan pihak ketiga untuk menilai apakah setiap anggota tim memiliki minat dan bakat pada usaha yang ditekuninya. Peserta yang mengetahui minat dan bakatnya akan lebih mengetahui potensi diri, sehingga memiliki kemampuan untuk bersaing (Maulidian, Sumiasih, Puspitawati, \& Indrawan, 2019). Strategi bersaing bertujuan untuk menghasilkan keunggulan bersaing dengan cara membangun dan mengembangkan potensi yang ada (Suhaeni, 2018).

Pada tahun 2020 dan 2021, DKI Jakarta mengalami wabah COVID19, sehingga segala aktifitas tatap muka ditiadakan. Oleh karena itu,PPKWB melakukan program seleksi melalui 2 tahap yang dilakukan secara daring yaitu tahap seleksi proposal dan seleksi wawancara. Seleksi proposal tidak dilakukan perubahan. Seleksi wawancara dilakukan melalui media daring. 


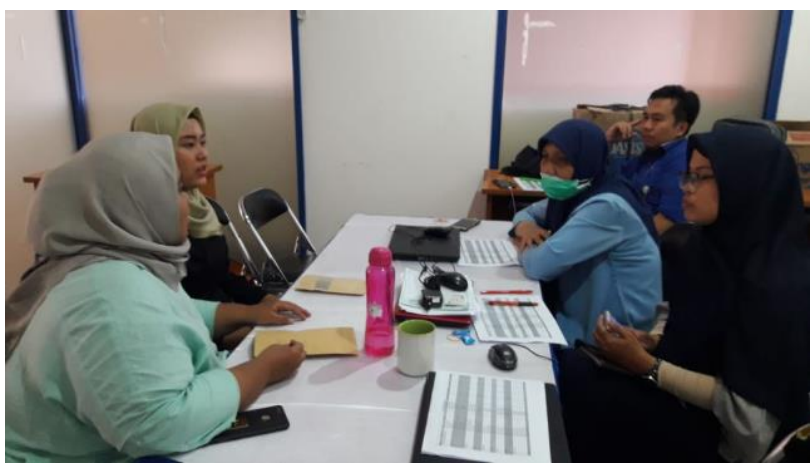

Gambar 1. Seleksi Wawancara Tatap Muka Tahun 2019

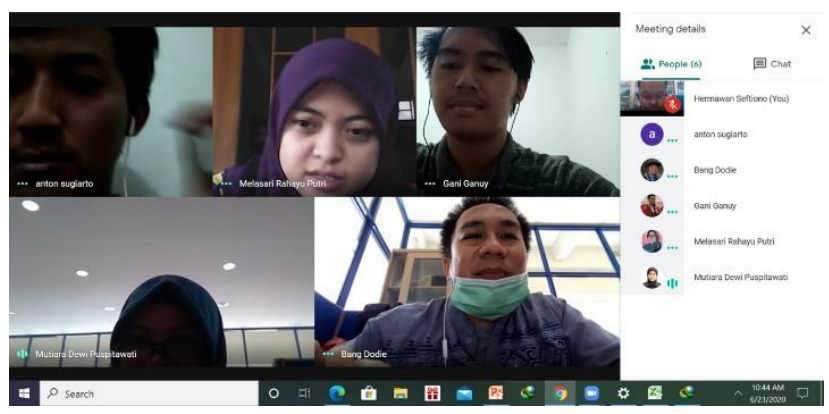

Gambar 2. Seleksi Wawancara Secara Daring Tahun 2020 dan 2021

\section{b. Program Kontrak dan Pendanaan} Kegiatan

Kontak kegiatan tenant program PPKWB tahun 2019 - 2021 dilakukan setelah peserta dinyatakan lolos seleksi. Kontrak berisikan perjanjian antara tim PPKWB dengan Peserta. Perjanjian pada umumnya berisikan tentang hak dan kewajiban kedua belah pihak selama program berangsung. Pada tahun 2019, kontrak dilakukan dengan tim yang lolos dan dihadiri oleh seluruh tim. Pada tahun 2020 dan 2021, kontrak dilakukan secara tatap muka yang dihadiri oleh ketua tim dengan memperhatikan protokol kesehatan.

Peserta yang telah menandatangi kontrak kegiatan akan diberi pendanaan pengembangan usaha. Kategori pendanaan yang diberikan pada Program PPKWB 2019 - 2021 yaitu pendanaan pengembangan produk, pendanaan komunikasi peserta, serta pendanaan bagi tiga peserta terbaik. Besaran pendanaan untuk pengembangan produk yaitu Rp. 2.500.000,- per tim. Pendanaan untuk komunikasi yaitu sebesar Rp. 100.000,- per bulan. Pendanaan untuk tiga peserta terbaik yaitu Rp. 2.500.000 per tim.

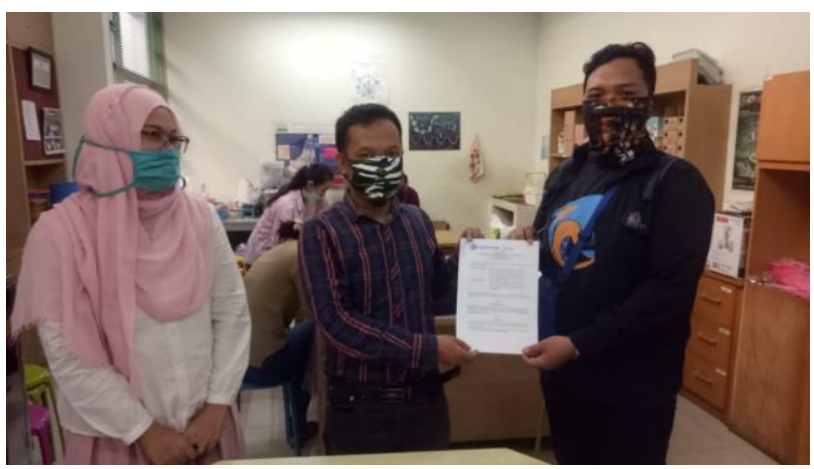

Gambar 4. Kontrak Kegiatan Tenant PPKWB

\section{c. Program Pendampingan}

Peserta yang telah melakukan kontrak dan pendanaan PPKWB 2019 - 2021 akan diberikan 1 (satu) orang mentor per tim. Mentor berfungsi untuk mengarahkan dan mendampingi peserta selama kegiatan agar target yang telah ditetapkan tercapai. Mentor berasal dari praktisi yang berpengalaman dibidang usaha atau professional. Jumlah kegiatan pendampingan minimal 2 kali dalam 1 (satu) bulan. Pada tahun 2019, program pendampingan dilakukan secara tatap muka. Tahun 2020 dan 2021, kegiatan pendampingan dilakukan secara daring.

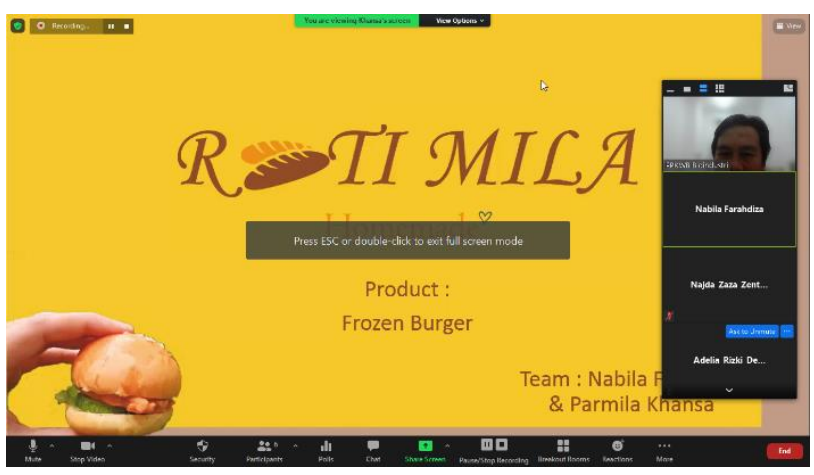

Gambar 5. Pendampingan Tenant Secara Daring

\section{d. Program Pelatihan}

Tahun 2019 pelatihan dilakukan secara tatap muka, sedangkan tahun 2020 dan 2021 pelatihan dilakukan secara daring. Kegiatan 
pelatihan yang diberikan kepada peserta terdiri dari 2 (dua) macam yaitu softskill wirausaha dan hardskill wirausaha. Materi softskill wirausaha yang diberikan yaitu menjadi wirausaha berbasis teknologi, Pola Pikir Perubahan, Kreatifitas Wirausaha, dan Memulai Usaha dengan Mengapa (Why). Adanya kreatifitas dan inovasi, mahasiswa memiliki senjata untuk menghadapi persaingan dalam industri (Hartini, 2012). Materi hardskill wirausaha yang diberikan yaitu perencanaan bisnis dengan SBM (Smart Business Map), Sanitasi dan Keamanan Pangan, Teknologi Kemasan Pangan, Inovasi Produk Pangan, Cara Produksi Pangan Olahan yang Baik (CPPOB), dan Hazard analysis and critical control points (HACCP).

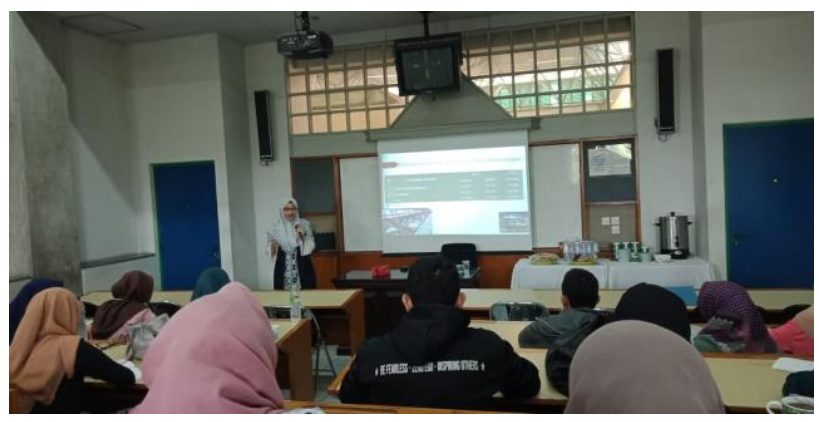

Gambar 6. Pelatihan Secara Tatap Muka

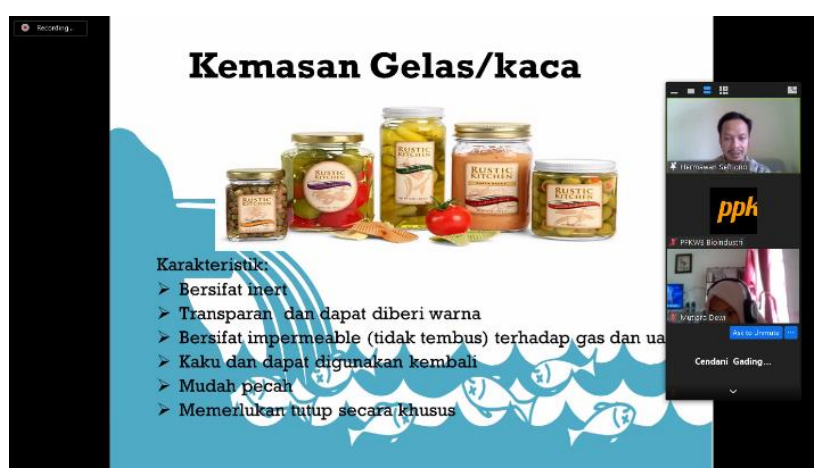

Gambar 7. Pelatihan Secara Daring

e. Program Kunjungan Perusahaan

Kegiatan kunjungan perusahaan dilakukan untuk memberikan peserta untuk belajar secara langsung dari perusahaan-perusahaan yang telah tumbuh dan besar dalam waktu yang cukup lama. Pengalaman-pengalaman yang berikan oleh perusahaan yaitu bagaimana perjuangan pada saat membangun usaha, bagaimana sistem produksi yang diterapkan, bagaimana sistem pemasaran yang dilakukan, bagaimana mengelola tim diperusahaan, serta bagaimana tips-tips membanguns usaha hingga besar. Tingkat produktivitas dalam usaha disebabkan oleh kurangnya pengatahuan dan pengalaman pelaku usaha, tidak memiliki jika kewirausahaan, serta kurangnya pengalaman dalam menjalankan usaha (Iskandar, 2017).

Pada tahun 2019, kunjungan perusahaan dilakukan secara tatap muka. Perusahaanperusahaan yang dikunjungi yang berada di daerah Jawa Timur yaitu Attaqie Farm, CV. Arjuna Flora, dan Kampung Cokelat. Pada tahun 2020 dan 2021, kunjungan perusahaan dilakukan secara daring atau virtual. Pada tahun 2020 kunjungan virtual dilakukan ke Attaqie Farm, Kawakibi, dan Klapetart Survivor. Tahun 2021 kunjungan perusahaan dilakukan ke Kawakibi, Ardena Food, dan Attaqie Farm. Adanya pengalaman mengikuti kunjungan perusahaan memberikan modal dasar untuk mahasiswa mendapatkan pengalaman dari industri yang sudah maju. Pengalaman pada pendidikan kewirausahaan juga merupakan modal dasar untuk berwirausaha (Utami, 2018).

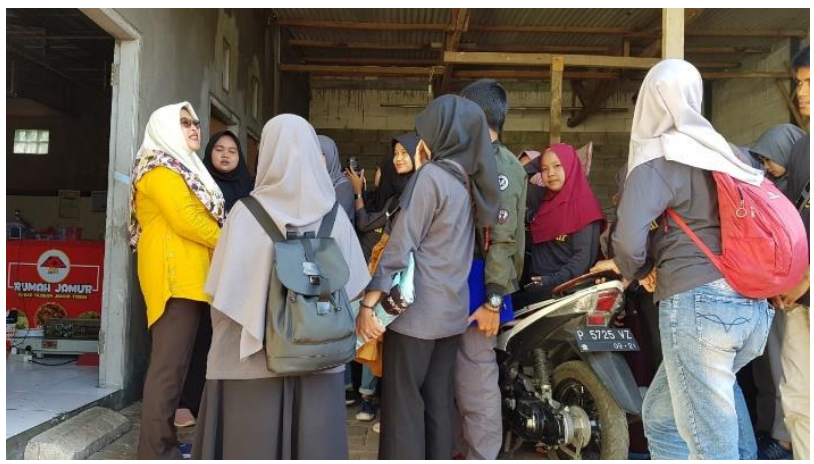

Gambar 8. Kunjungan Perusahan Ke CV. Arjuna Flora tahun 2019

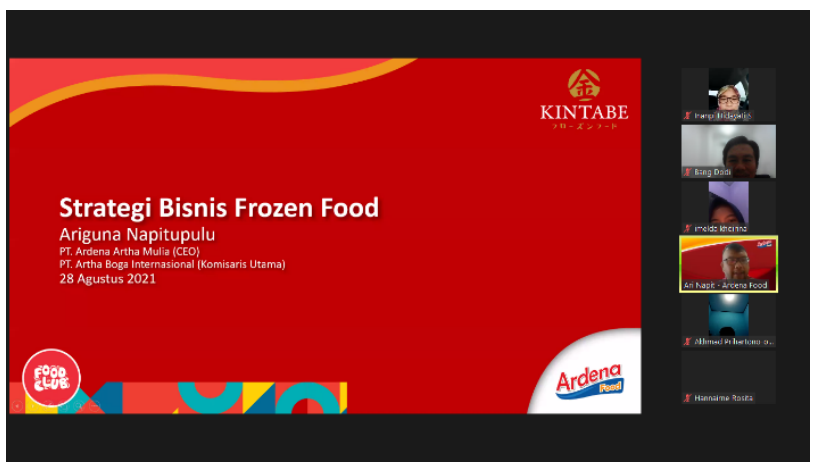




\section{Gambar 9. Virtual Company Visit Ke Ardena Food Tahun 2021}

\section{Monitoring dan Evaluasi}

Kegiatan monitoring dan evaluasi dilakukan untuk melihat sejauh mana hasil dan kemajuan setelah mengikuti program-program PPKWB 20192021. Monitoring dilakukan oleh pendamping peserta kegiatan untuk melihat kemajuan-kemajuan dari usaha yang dijalankan. Pendamping akan memberikan hasilnya kepada tim PPKWB, sejauh mana perkembangan dari usaha yang dijalankan. Evaluasi kegiatan dilakukan pada bulan September, untuk menilai kemajuan peserta dalam mengikuti program kegiatan. Hasil evaluasi untuk menilai apakah peserta layak lulus dalam program kegiatan dan juga untuk menilai 3 tim terbaik selama program kegiatan. Kategori penilaian yaitu kemajuan produk inovasi sebelum dan sesudah mengikuti program, kemajuan sistem pemasaran, dan laporan bisnis serta adminsitrasi keuangan. Hasil kegiatan monev program PPKWB tahun 2019, 2020 dan 2021 dapat dilihat pada Tabel 1, Tabel 2, dan Tabel 3.

\section{Tabel 1. Hasil Kegiatan Monev Program PPKWB tahun 2019}

\begin{tabular}{|c|c|c|}
\hline Tim & Penanggung Jawab & Kemajuan \\
\hline Sarbika & Fitri Yani & $\begin{array}{c}\text { Dari Carpy } \\
\text { menjadi Biocraft } \\
\text { (Pivot) }\end{array}$ \\
\hline MoodUp & Arbi Robiansyah & $\begin{array}{l}\text { Produk dan } \\
\text { kemasan Lebih } \\
\text { Baik }\end{array}$ \\
\hline Kinoko & $\begin{array}{l}\text { Rosa qhoiriyah } \\
\text { cahyanda }\end{array}$ & $\begin{array}{c}\text { Ganti Nama- } \\
\text { Kinoque, Produk } \\
\text { Lebih Baik }\end{array}$ \\
\hline Sooci & $\begin{array}{c}\text { Juniawan Ahmad } \\
\text { Arif S }\end{array}$ & $\begin{array}{l}\text { Inovasi, Kemasan, } \\
\text { Kesiapan di Pasar }\end{array}$ \\
\hline Mopizza & Siti Windari & $\begin{array}{l}\text { Inovasi, Kemasan, } \\
\text { Kesiapan di Pasar }\end{array}$ \\
\hline Iso-Gen & Ugan Suganda & $\begin{array}{l}\text { Ganti Kemasan, } \\
\text { Produk Lebih Baik }\end{array}$ \\
\hline
\end{tabular}

\begin{tabular}{|c|c|c|}
\hline Otel & Iqbal Ramadan & $\begin{array}{l}\text { Ganti Kemasan, } \\
\text { Produk Lebih Baik }\end{array}$ \\
\hline Mapaya & $\begin{array}{l}\text { Nurfitriyani } \\
\text { Barokah }\end{array}$ & $\begin{array}{c}\text { Perbaikan } \\
\text { Kemasan, Produk } \\
\text { Lebih Baik }\end{array}$ \\
\hline Buna Tea & Parmila Khansa & $\begin{array}{l}\text { Inovasi, Kemasan, } \\
\text { Kesiapan di Pasar }\end{array}$ \\
\hline Muma & $\begin{array}{l}\text { Nadhilah } \\
\text { Lahabibah }\end{array}$ & $\begin{array}{l}\text { Inovasi, Kemasan, } \\
\text { Kesiapan di Pasar }\end{array}$ \\
\hline Yoshee & $\begin{array}{l}\text { Herdiana } \\
\text { Cyntiawati }\end{array}$ & $\begin{array}{c}\text { Perbaikan } \\
\text { Kemasan, Produk } \\
\text { Lebih Baik }\end{array}$ \\
\hline Nature B & Irna Rahmawati & $\begin{array}{l}\text { Inovasi, Kemasan, } \\
\text { Kesiapan di Pasar }\end{array}$ \\
\hline
\end{tabular}

Tabel 2. Hasil Kegiatan Monev Program PPKWB tahun 2020

\begin{tabular}{|c|c|c|}
\hline Tim & Penanggung Jawab & Kemajuan \\
\hline Potka & $\begin{array}{c}\text { Melasari Rahayu } \\
\text { Putri }\end{array}$ & $\begin{array}{l}\text { Pengembangan } \\
\text { produk }\end{array}$ \\
\hline Vegefish & $\begin{array}{c}\text { Akhmad } \\
\text { Prihartono }\end{array}$ & $\begin{array}{l}\text { Nama brand, } \\
\text { Pengembangan } \\
\text { Produk }\end{array}$ \\
\hline Kripca & $\begin{array}{l}\text { Alvianty } \\
\text { Ramadhani } \\
\text { Indrianto }\end{array}$ & $\begin{array}{l}\text { Pengembangan } \\
\text { Produk, Pivot dari } \\
\text { Albedo menjadi } \\
\text { kripca }\end{array}$ \\
\hline Burgernesia & $\begin{array}{l}\text { Amara Vhalufi } \\
\text { maharani }\end{array}$ & $\begin{array}{c}\text { Outlet, Nama } \\
\text { brand, Varian rasa, } \\
\text { Distribusi dan } \\
\text { kemasan }\end{array}$ \\
\hline Roti Karkus & $\begin{array}{l}\text { Rizky Muhammad } \\
\text { Adi Perdana }\end{array}$ & $\begin{array}{c}\text { Outlet, Kemasan, } \\
\text { Varian Rasa, dan } \\
\text { Distribusi }\end{array}$ \\
\hline YubiNugget & Anggie Yulianti & $\begin{array}{l}\text { Pengembangan } \\
\text { Produk }\end{array}$ \\
\hline Pyong Kitchen & gabriella rezki & $\begin{array}{l}\text { Nama Brand, } \\
\text { Varian produk, } \\
\text { Kemasan, }\end{array}$ \\
\hline
\end{tabular}




\begin{tabular}{|c|c|c|}
\hline & & Distribusi \\
\hline Indorice & Duwi Apriyani & $\begin{array}{c}\text { Pengembangan } \\
\text { Produk }\end{array}$ \\
\hline Bubblely Bob's & Khamila Putri & $\begin{array}{c}\text { Nama Brand, } \\
\text { Varian Rasa, } \\
\text { Kemasan }\end{array}$ \\
\hline Fancis Jam & Hana Pratiwi & $\begin{array}{c}\text { Nama Brand, } \\
\text { Kemasan }\end{array}$ \\
\hline Rainbowlu & $\begin{array}{l}\text { Lidya Alisa } \\
\text { Maudyna }\end{array}$ & $\begin{array}{c}\text { Pengembangan } \\
\text { Produk }\end{array}$ \\
\hline Saritem & $\begin{array}{l}\text { Dennis Okta } \\
\text { Kurniawan }\end{array}$ & $\begin{array}{c}\text { Pengembangan } \\
\text { Produk }\end{array}$ \\
\hline
\end{tabular}

Tabel 3. Hasil Kegiatan Monev Program PPKWB tahun 2021

\begin{tabular}{|c|c|c|}
\hline Tim & Penanggung Jawab & Kemajuan \\
\hline Frozen burger & Parmila Khansa & $\begin{array}{c}\text { Perbaikan Inovasi } \\
\text { Produk dan } \\
\text { Penjualan }\end{array}$ \\
\hline $\begin{array}{l}\text { Bakso Frozen } \\
\text { Prebiotik }\end{array}$ & $\begin{array}{l}\text { Najda Zaza } \\
\text { Zentaliana }\end{array}$ & $\begin{array}{l}\text { Perbaikan kemasan } \\
\text { dan inovasi produk }\end{array}$ \\
\hline Shicimol & Silvia anggraeni & $\begin{array}{l}\text { Perbaikan inovasi } \\
\text { produk dan } \\
\text { penjualan }\end{array}$ \\
\hline $\begin{array}{c}\text { DKG (Dapur } \\
\text { Kakak Gembira) }\end{array}$ & Imelda Khoirina & $\begin{array}{c}\text { Perbaikan Inovasi } \\
\text { produk dan } \\
\text { peningkatan } \\
\text { penjualan }\end{array}$ \\
\hline Ngenyangin & $\begin{array}{l}\text { Rosa qhoiriyah } \\
\text { cahyanda }\end{array}$ & $\begin{array}{c}\text { Perbaikan kemasan } \\
\text { dan peningkatan } \\
\text { penjualan }\end{array}$ \\
\hline Otakin aja & Diana Safitri & Perbaikan Produk \\
\hline Pudding Custom & Hannairne Rosita & $\begin{array}{l}\text { Perbaikan inovasi } \\
\text { produk, dan } \\
\text { peningkatan } \\
\text { penjualan }\end{array}$ \\
\hline S-Hat & $\begin{array}{l}\text { Rizky Muhammad } \\
\text { Adi Perdana }\end{array}$ & $\begin{array}{l}\text { Perbaikan inovasi } \\
\text { produk, } \\
\text { penmabhan cabang }\end{array}$ \\
\hline
\end{tabular}

dan penjualan

\section{KESIMPULAN}

Hasil kegiatan dari program-program PPKWB 2019-2021 dirasakan manfaatnya oleh peserta. Peserta-peserta terbaik yang telah lulus program dapat meningkatkan skala usahanya dari segi omset, jumlah karyawan dan cabang usaha. Program seleksi bermanfaat untuk menyaring peserta yang bersungguh ingin mengembangan usahanya. Program kontrak dan pendanaan bermanfaat untuk meminimalisir risiko dalam pengembangan produk inovasi peserta. Program pendampingan bermanfaat untuk mengarahkan peserta ketika peserta mengalami kebuntuan dalam menjalan usahanya. Kegiatan pelatihan bermanfaat bagi peserta untuk menambah pengetahuan dan memperbaiki sikap dalam berwirausaha. Kegiatan kunjungan perusahaan memberikan inspirasi bagi peserta agar memiliki impian yang sama.

\section{UCAPAN TERIMAKASIH}

Tim PPKWB mengucapkan terima kasih kepada Kemendikbudristek yang telah mempercayakan kepada kami untuk mengelola dana Hibah PPK Simlitabmas, Universitas Trilogi yang telah memberikan sarana dan prasarana guna kelancaran kegiatan ini, serta perusahaanperusahaan mitra yang telah memberikan pengalaman dan ilmu kepada peserta PPKWB tahun 2019-2021.

\section{REFERENSI}

Athia, A., Saraswati, E., \& Normaladewi, A. (2018). enerapan Business Model Canvas (BMC) Untuk Mendorong Mindset Kewirausahaan di Kalangan Mahasiswa Universitas Islam Malang. Jurnal Ketahanan Pangan, 2(1): 66-75.

Budi, \& Fensi, F. (2018). Pendidikan Kewirausahaan Dalam Menumbuhkan Minat Berwirausaha. Jurnal Pengabdian dan 
Kewirausahaan. Jurnal Pengabdian dan Kewirausahaan, 2(1): 1-9.

Hartini, S. (2012). Peran Inovasi Pengembangan Kualitas Produk dan Kinerja Bisnis. Jurnal Manajemen dan Kewirausahaan, 14(1): 8288.

Iskandar. (2017). Pengaruh Kewirausahaan dan Peluang Pasar terhadap kinerja usaha Perdagangan Mikro Kecil dan Menengah di Kecamatan Peureulak Kota Kabupaten Aceh timur. Jurnal Samudra Ekonomi dan Bisnis, 8(1): 611618.

Maulidian, Sumiasih, I. H., Puspitawati, M. D., \& Indrawan, I. (2019). Pola Seleksi Berdasarkan Minat dan Bakat pada Calon Tenant Wirausaha Fakultas Bioindustri Universitas Trilogi. Abdihaz: Jurnal Ilmiah Pengabdian pada Masyarakat, 1(2) : 45-52.

Rosmiati, Junias, D., \& Munawar. ( 2015). Sikap, Motivasi, dan Minat Berwirausaha Mahasiswa. Jurnal Manajemen dan Kewirausahaan, 17(1): 21-30.

Setyawati, E., Nugraha, H., \& Ainuddin, I. (2013). Karakteristik Kewirausahaan dan Lingkungan Bisnis Sebagai Faktor Penentu Pertumbuhan Usaha (Studi IKM di Sentra Kerajinan Rotan Amuntai Kab.Hulu Sungai Utara, Provinsi Kalimantan Selatan. Jurnal Administrasi Bisnis, 2(1): 41-50.

Suhaeni, T. (2018). Pengaruh Strategi Inovasi Terhadap Keunggulan Bersaing di Industri Kreatif (Studi Kasus UMKM Bidang Kerajinan Tangan di Kota Bandung). Jurnal Riset Bisnis dan Investasi, 4(1): 57-74.

Sukirman. (2017). Jiwa Kewirausahaan dan Nilai Kewirausahaan Meningkatkan Kemandirian Usaha Melalui Perilaku Kewirausahaan. Jurnal Ekonomi dan Bisnis, 20(1): 113-132.

Utami, R. (2018). Hubungan Antara Jiwa Wirausaha Mahasiswa Dengan Motivasi, Lingkungan Keluarga dan Pendidikan Pada Politeknik LP3I Jakarta Kampus Cimone. Jurnal Lentera Bisnis, 7(1): 82-96.
Widayati, E., Yunaz, H., Rambe, T., Siregar, B., Fauzi, A., \& Romli. (2019). Pengembangan Kewirausahaan Dengan Menciptakan Wirausaha Baru dan Mandiri. Jurnal Ilmiah Manajemen Bisnis dan Inovasi, 6(2): 98105. 